\title{
Identification of eQTLs for Hepatic Xbp1s and Socs3 Gene Expression in Mice Fed a High-Fat, High-Caloric Diet
}

\author{
Sarina Pasricha, ${ }^{\star \dagger}{ }^{\dagger}$ Jane Kenney-Hunt, ${ }^{*}$ Kristy Anderson, ${ }^{\star}$ Nadereh Jafari, ${ }^{\S}$ Rabea A. Hall, ${ }^{\star \star}$ \\ Frank Lammert, ${ }^{\star \star}$ James Cheverud, ${ }^{\dagger+}$ and Richard M. Green*,1 \\ *Department of Internal Medicine, Northwestern University, Chicago, Illinois, ${ }^{\dagger}$ Department of Internal Medicine, \\ University of North Carolina, Chapel Hill, North Carolina, ‡Department of Biology and Environmental Science, \\ Westminster College, Fulton, Missouri, §Center for Genetic Medicine, Northwestern University, Chicago, Illinois, \\ ${ }^{* *}$ Department of Medicine II, Saarland University Medical Center, Homburg, Germany, and ${ }^{\dagger+}$ Department of Biology, \\ Loyola University, Chicago, Illinois
}

\begin{abstract}
Nonalcoholic fatty liver disease (NAFLD) is a highly prevalent form of human hepatic disease and feeding mice a high-fat, high-caloric (HFHC) diet is a standard model of NAFLD. To better understand the genetic basis of NAFLD, we conducted an expression quantitative trait locus (eQTL) analysis of mice fed a HFHC diet. Two-hundred sixty-five (A/J $\times$ C57BL/6J) $F_{2}$ male mice were fed a HFHC diet for 8 wk. eQTL analysis was utilized to identify genomic regions that regulate hepatic gene expression of Xbp1s and Socs3. We identified two overlapping loci for Xbp1s and Socs3 on Chr 1 (164.0-185.4 Mb and 174.4-190.5 Mb, respectively) and Chr 11 (41.1-73.1 Mb and 44.0-68.6 Mb, respectively), and an additional locus for Socs3 on Chr 12 (109.9-117.4 Mb). C57BL/6J-Chr 11A/J/ NaJ mice fed a HFHC diet manifested the A/J phenotype of increased Xbp1s and Socs3 gene expression $(P<0.05)$, whereas C57BL/6J-Chr $1 \mathrm{~A} / \mathrm{J} / \mathrm{NaJ}$ mice retained the C57BL/6J phenotype. In addition, we replicated the eQTLs on Chr 1 and Chr 12 (LOD scores $\geq 3.5$ ) using mice from the BXD murine reference panel challenged with $\mathrm{CCl}_{4}$ to induce chronic liver injury and fibrosis. We have identified overlapping eQTLs for Xbp1 and Socs3 on Chr 1 and Chr 11, and consomic mice confirmed that replacing the C57BL/6J Chr 11 with the A/J Chr 11 resulted in an A/J phenotype for Xbp1 and Socs3 gene expression. Identification of the genes for these eQTLs will lead to a better understanding of the genetic factors responsible for NAFLD and potentially other hepatic diseases.
\end{abstract}

KEYWORDS

eQTLs

mice

fatty

liver
Nonalcoholic fatty liver disease (NAFLD) is the most common cause of abnormal liver function tests and is one of the most frequent causes of chronic liver disease in the United States. NAFLD has a prevalence as high as $30 \%$ in the general population and $75 \%$ in obese patients (Lazo and Clark 2008; Reid 2001; Wanless and Lentz 1990; Browning

Copyright $\odot 2015$ Pasricha et al.

doi: $10.1534 / \mathrm{g} 3.115 .016626$

Manuscript received August 26, 2014; accepted for publication January 20, 2015; published Early Online January 23, 2015.

This is an open-access article distributed under the terms of the Creative Commons Attribution Unported License (http://creativecommons.org/licenses/ by/3.0/), which permits unrestricted use, distribution, and reproduction in any medium, provided the original work is properly cited.

Supporting information is available online at http://www.g3journal.org/lookup/ suppl/doi:10.1534/g3.115.016626/-/DC1

Reference Numbers: GEO GSE56987, GeneNetwork GN325.

${ }^{1}$ Corresponding author: Northwestern University Feinberg School of Medicine,

Tarry Building 15-719, 303 East Chicago Avenue, Chicago, IL 60611.

E-mail: r-green2@northwestern.edu and Horton 2004). NAFLD represents a spectrum of diseases, including simple steatosis, nonalcoholic steatohepatitis (NASH) with or without fibrosis, cirrhosis, and end-stage liver disease. NAFLD has been closely linked to the metabolic syndrome characterized by obesity, dyslipidemia, and insulin resistance (Ron and Walter 2007; Vanni et al. 2010; Speliotes et al. 2008; Speliotes et al. 2010). Liver-related and overall mortality rates are significantly higher in patients with NAFLD compared with the general population (Ong et al. 2008). In fact, it is estimated that NAFLD/cryptogenic cirrhosis will be the leading indication for liver transplantation within a decade. Despite the high prevalence of NAFLD, the pathogenesis and genetic mechanisms responsible for the susceptibility and progression of NAFLD remain poorly understood.

Several studies support the important role of genetics in the pathogenesis of nonalcoholic steatohepatitis (Willner et al. 2001; Angulo 2002; Silverman et al. 1989; Wagenknecht et al. 2009). NASH is a polygenic disease in which susceptible individuals can develop disease when exposed to environmental factors such as excess calorie intake, obesity, and insulin resistance (Speliotes et al. 2008; Willner et al. 
2001; Angulo 2002). The unfolded protein response (UPR) is a protective cellular signaling response that is activated in response to endoplasmic reticulum (ER) stress, and the hepatic UPR is activated by insulin resistance, obesity, and fatty liver (Cnop et al. 2012; Eizirik et al. 2008; Ji and Kaplowitz 2006; Brenner et al. 2013). In fact, X-box binding protein-1 spliced $(X b p 1 s)$ is a key regulator of the UPR and dysregulation of hepatic Xbp1s has been shown to be important in the pathogenesis of human nonalcoholic fatty liver diseases (Puri et al. 2008). Xbp1s is the spliced form of Xbp1 that occurs when the Xbp1 transcript is spliced by Inositol Requiring Kinase 1- $\alpha$ (IRE1 $\alpha$ ) in response to ER stress. When this occurs, Xbp1s regulates the expression of its down-stream target genes (Ron and Walter 2007; Puri et al. 2008; Kaser et al. 2008; Tilg and Moschen 2010; Lee et al. 2008).

Suppressor of Cytokine Signaling 3 (SOCS3) is an inflammatory mediator that has also been previously identified to be important in glucose and lipid metabolism, and it has been implicated in the pathogenesis of experimental models of NAFLD (Wang et al. 2009; Ihle 1995; Handy et al. 2011; Brenner et al. 2013; Moschen et al. 2010; Clementi et al. 2009; Ogawa and Kasuga 2008; Ueki et al. 2005; Tilg 2010). In fact, when mice with a liver-specific deletion of Socs 3 are fed a high-fat diet, they develop increased liver fat and inflammation compared with control mice (Sachithanandan et al. 2010). Therefore, both human and murine studies demonstrate that hepatic XBP1s and SOCS3 expression are important in the pathogenesis of fatty liver diseases.

Quantitative trait loci (QTL) analysis is a well-established genetic technique for mapping the chromosomal loci of complex traits in rodents, humans, multiple animals, and plants (Rapp 2000; Paterson et al. 1991; Fullerton et al. 2003). QTL analysis using experimental crosses of mice has been successfully applied to identify QTL in several polygenic diseases of the metabolic syndrome, including obesity, diabetes, and hypertension ( $\mathrm{Mu}$ et al. 1999; Pomp 1997; Wang et al. 2012). The aim of this investigation is to utilize the high-fat, highcaloric (HFHC) dietary model of murine fatty liver disease and eQTL analysis in an $\mathrm{F}_{2}$ intercross of $\mathrm{C} 57 \mathrm{BL} / 6 \mathrm{~J}$ and $\mathrm{A} / \mathrm{J}$ mice to identify eQTLs and candidate genes that are important in the pathogenesis and progression of NAFLD. In addition, we tested allele effects of candidate regions in consomic strains (C57BL/6J-Chr $1^{\mathrm{A} / \mathrm{J} / \mathrm{NaJ}}$ and

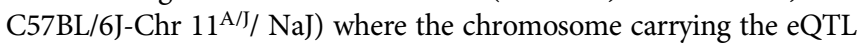
region has been substituted from the $\mathrm{A} / \mathrm{J}$ background into a C57BL/6J background.

To help determine the relevance of the identified loci in other forms of liver injury, we used the $\mathrm{CCl}_{4}$ hepatotoxicity model and the BXD murine reference panel for systems genetics (Andreux et al. 2012). BXD mice are recombinant inbred lines generated from $F_{1}$ hybrids of $\mathrm{C} 57 \mathrm{BL} / 6 \mathrm{~J}$ and $\mathrm{DBA} / 2 \mathrm{~J}$ mice by consecutive brother-sister matings of the $\mathrm{F}_{2}$ progeny for more than 20 generations. These genetically mosaic lines are homozygous at every genetic locus and represent a panel that has been extensively genotyped across the genomes.

Identifying candidate NAFLD genes will be essential for enhancing our understanding of the genetic factors that are important in the pathogenesis and progression of NAFLD and in subsequently developing rational therapeutic strategies for this common liver disease.

\section{MATERIALS AND METHODS}

\section{Animals}

A/J, C57BL/6J, B6AF1/J, C57BL/6J-Chr 1 1 /J/ NaJ, and C57BL/6J-Chr $11^{\mathrm{A} / J} / \mathrm{NaJ}$ male mice were purchased from Jackson Laboratory (Bar Harbor, ME). A/J and C57BL/6J mice were chosen following a pre- liminary screen of six mouse strains (A/J, C57BL/6J, DBA-2J, AKR/J, $129 \times 1 / \mathrm{SvJ}$ ) for hepatic expression of Xbp1s and Socs3. The A/J and C57BL/6J recombinant inbred (RI) strains of mice had no significant differences in baseline hepatic Xbp1s and Socs3 expression when fed chow, yet elicited different susceptibilities of hepatic Xbp1s and Socs3 gene expression when fed the high-fat diet. C57BL/6J-Chr $1^{\mathrm{A} / \mathrm{J} / \mathrm{NaJ}}$ mice are chromosome substitution strains (CSS) of consomic mice where chromosome 1 from strain $\mathrm{A} / \mathrm{J}$ has been substituted on a C57BL/ $6 \mathrm{~J}$ background; C57BL/6J-Chr $11^{\mathrm{A} / \mathrm{J} / \mathrm{NaJ}}$ mice are CSS mice where chromosome 11 from strain $\mathrm{A} / \mathrm{J}$ has been substituted into a C57BL/ 6J background. Chromosomes 1 and 11 substitute lines were selected because eQTLs for both Xbp1s and Socs3 localized to these chromosomes. B6AF1/J mice are an $\mathrm{F}_{1}$ hybrid of $\mathrm{C} 57 \mathrm{BL} / 6 \mathrm{~J}$ female and $\mathrm{A} / \mathrm{J}$ male mice, and these mice were crossed to generate $265 \mathrm{~F}_{2}$ generation mice from 74 litters that were used for eQTL analysis. Male 8to 10 -wk-old mice were used for all experiments because differences in hepatic Xbp1s and Socs3 expression were slightly greater in male compared with female mice. We also analyzed $30 \mathrm{BXD}$ recombinant inbred lines with an average of six mice per sex and line. Mice were purchased (BXD lines 1, 2, 6, 11, 12, 13, 14, 19, 24a, 27, 28, 31, 32, $33,34,39,40,42,96$, and 98) from Jackson Laboratory and (BXD lines 43, 51, 55, 62, 65, 69, 73, 75, 87, and 90) from Oak Ridge Laboratory. All animal protocols were approved by the Northwestern University Institutional Animal Care and Use Committee (IACUC) or according to all relevant welfare regulations of the Animal Care and Use Committee for Saarland University that approved the protocols (TV 10/2008).

\section{Phenotypic analysis of mice}

In HFHC diet feeding studies, A/J, C57BL/6J, C57BL/6J-Chr 1 1 /J/ NaJ,

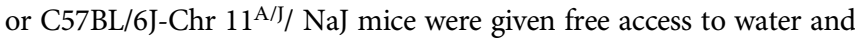
a HFHC diet (60\% fat, 20\% protein, 20\% carbohydrates; D12492; Research Diets, New Brunswick, NJ) for $8 \mathrm{wk}$. Body weight was recorded after 0,4 , and $8 \mathrm{wk}$ of dietary feeding. After $8 \mathrm{wk}$, the mice were killed using $\mathrm{CO}_{2}$ narcosis after a 4 -hr fast, and blood was collected by cardiac puncture. The liver and spleen were rapidly excised, rinsed in ice-cold saline, weighed, and snap-frozen in liquid nitrogen. Tails were clipped and snap-frozen in liquid nitrogen and stored at $-80^{\circ}$ until analyzed. To assess for liver injury and components of the metabolic syndrome, hepatic triglyceride levels were measured enzymatically on liver homogenate according to the manufacturer (Pointe Scientific, Canton MI); serum alanine aminotransferase (ALT) was measured using a spectrophotometric assay kit (Biotron, Hemet, CA). Serum glucose was measured by the glucose oxidase method using a colorimetric meter (Glucose Assay Kit). Serum insulin levels were determined using the Meso Scale Discovery system (Gaithersburg, MD). Quantitative insulin sensitivity check index (QUICKI) was calculated using 4-hr fasting insulin and glucose levels. In RT-PCR experiments, total RNA isolation and reverse-transcription were performed from liver using Trizol (Invitrogen) and qScript One-Step CYBR Green qRT-PCR (Quanta Biosciences). Xbp1s forward primers were sense $5^{\prime}$-AAGAACACGCTTGGGAATGG-3' and Xbp1s reverse primers were anti-sense $5^{\prime}$-CTGCACCTGCTGCGGAC- $3^{\prime}$. Socs 3 forward primers were sense $5^{\prime}$-CCCTTGCAGTTCTAAGTTCAACA-3' and Socs 3 reverse primers were anti-sense $5^{\prime}$-ACCTTTGACAAGCG GACTCTC-3'. Gapdh was used as an internal control and was unchanged under the experimental condition. Studies were performed in

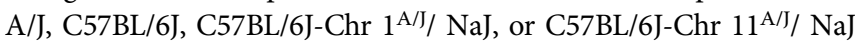
and $\mathrm{F}_{2}(\mathrm{~A} / \mathrm{J} \times \mathrm{C} 57 \mathrm{BL} / 6 \mathrm{~J})$ mice. Comparisons were performed using 
Student's $t$-test or ANOVA, and the Tukey range test was performed as a post-hoc test.

\section{eQTL analysis of mice fed a high-fat, high-caloric diet}

DNA was extracted from mouse tails and medium density linkage panel genotyping was performed at the Center of Genomic Studies at Northwestern University using Illumina Medium Density Microarray Chips (Illumina, San Diego, CA); 959 polymorphic SNPs were identified between $\mathrm{C} 57 \mathrm{BL} / 6 \mathrm{~J}$ and the $\mathrm{A} / \mathrm{J}$ parental strains, and genotyping and phenotyping for hepatic gene expression were performed on $265 \mathrm{~F}_{2}$ male mice. eQTL analysis was performed using R/qtl (Broman et al. 2003). Genome-wide 5\% significance thresholds were generated in R/qtl using the scanone function and 1000 permutations. The LOD threshold for autosomes is 3.91 and is 2.87 for the $\mathrm{X}$ chromosome. Additional chromosome-wide 5\% significance thresholds were generated using the method of $\mathrm{Li}$ and Ji (2005) (Chen and Storey 2006). The phenotypes of Xbp1s, Socs3, glucose, and insulin were log-transformed before analysis. SNP genomic positions obtained from Ensembl.org, build GRCm38. p3. Genes, predicted genes, and differential SNPs and nsSNPs were obtained from Mouse Genome Informatics Database (MGI 5.20). eQTL regions are defined as the 1.0 LOD-drop of both sides of the peak of the eQTL. The SNP marker closest to the 1.0 LOD-drop was utilized as the physical boundary of the interval. $X b p 1$ is located at Chr11: 5,520,659-5,525,893; murine Socs3 is at Chr11: $117,966,079-117,970,047$ bp.

\section{Microarray analysis of mice fed a high-fat, high-caloric diet}

For microarray studies analyzing the differentially expressed hepatic genes between $\mathrm{A} / \mathrm{J}$ and $\mathrm{C} 57 \mathrm{BL} / 6 \mathrm{~J}$ mice, analysis was performed using a minimum of three samples of hepatic mRNA, with each sample pooled from two mice (San Diego, CA). We utilized Illumina Mouse Ref 8 chips containing 25,697 probes of 18,708 genes. All samples met the Illumina standard quality control checks. Data quality checks were performed using the Bioconductor Lumi package for $\mathrm{R}$ statistical programming environment. The intensity distribution of the samples was examined by histogram and box plots. The data processing also includes a normalization procedure utilizing a quantile normalization method (Bolstad et al. 2003) to reduce the obscuring variation between microarrays, which might be introduced during the processes of sample preparation, manufacture, fluorescence labeling, hybridization, and/or scanning. Hierarchical clustering and principal component analysis were performed on the normalized signal data to assess the sample relationship and variability.

Using the criteria that a probe is considered not to be expressed if no probes' background $P$ value was less than $0.01,13,060$ out of 25,697 probes were kept for further differential gene expression analyses. A modified $t$-test using limma's algorithm of fitting to linear models was used to obtain an adjusted $P$ value, using the Benjamini-Hochberg method to estimate the false discovery rate. For each requested comparison, genes that showed a fold-change in expression of at least 1.5 and an adjusted $P$ value of 0.05 or less were considered differentially expressed. The probes' genes were identified using the lumiMouse DB package (Bolstad et al. 2003).

\section{eQTL analysis of BXD mice treated with carbon tetrachloride $\left(\mathrm{CCl}_{4}\right)$}

Mice from C57BL/6J, DBA/2J, B6D2 F1 hybrids and $30 \mathrm{BXD}$ recombinant inbred lines were phenotyped for hydroxyproline levels and collagen areas after induction of chronic liver injury and fibrosis using $\mathrm{CCl}_{4} \cdot \mathrm{CCl}_{4}(0.7 \mathrm{mg} / \mathrm{kg}$ body weight, in a $1: 1$ mixture withmineral oil) was administered for $6 \mathrm{wk}$ with two intraperitoneal injections per week. The mice do not develop fibrosis when fed a chow diet without the administration of $\mathrm{CCl}_{4}$. We measured hepatic collagen contents (hydroxyproline levels and collagen areas) as quantitative parameters and fibrosis stages as semiquantitative measures in histological liver sections as previously described (Hall et al. 2014). Phenotypic characterization of hepatic collagen was initially performed in male and female mice. Transcriptomes of $\mathrm{CCl}_{4}$-treated BXD lines were analyzed in female mice (three arrays per line) because they showed more pronounced differences in fibrosis progression among the BXD lines. The mice were chow-fed and the transcriptome of three female mice from each BXD line after $\mathrm{CCl}_{4}$ challenge was determined with Affymetrix Mouse Gene 1.0 ST microarrays. These data underwent quality control and normalization and were uploaded into the GeneNetwork database (http:// www.genenetwork.org/webqtl/main.py). Using the gene expression values as quantitative traits, interval mapping was performed to identify eQTLs as implemented in GeneNetwork.

\section{RESULTS}

\section{Hepatic Xbp1s and Socs3 gene expression in $\mathrm{A} / \mathrm{J}$ and C57BL/6J mice fed a HFHC diet}

Parental mouse strains C57BL/6J and A/J fed a HFHC diet for $8 \mathrm{wk}$ elicited significant differences in the hepatic gene expression of $\mathrm{Xbp} 1 \mathrm{~s}$ : $1.0 \pm 0.2$ vs. $0.4 \pm 0.2$ in $\mathrm{A} / \mathrm{J}$ and $\mathrm{C} 57 \mathrm{BL} / 6 \mathrm{~J}$ mice, respectively $(P<$ $0.05)$. There was also a similar difference in hepatic Socs 3 gene expression: $1.0 \pm 0.2$ vs. $0.6 \pm 0.2 \mathrm{in} \mathrm{A} / \mathrm{J}$ and $\mathrm{C} 57 \mathrm{BL} / 6 \mathrm{~J}$ mice, respectively $(P<0.05)$. Hepatic Xbp1s and Socs3 gene expression in $\mathrm{F}_{1}$ $(\mathrm{A} / \mathrm{J} \times \mathrm{C} 57 \mathrm{BL} / 6 \mathrm{~J})$ mice was $0.7 \pm 0.1$ for $\mathrm{Xbp} 1 \mathrm{~s}$ and $0.7 \pm 0.2$ for Socs3 $(P<0.05)$, both significantly different from $\mathrm{A} / \mathrm{J}$ mice. Hepatic $X b p 1 s$ expression also differed between the $\mathrm{F}_{1}(\mathrm{~A} / \mathrm{J} \times \mathrm{C} 57 \mathrm{BL} / 6 \mathrm{~J})$ and C57BL/6J mice (Figure 1; $\mathrm{n}=8$ for all groups). Supporting Information, Table $\mathrm{S} 1$ shows the Pearson correlation matrix of the phenotypes $\mathrm{Xbp} 1 \mathrm{~s}$ and Socs3 in C57BL/6J and A/J mice (as well as for several phenotypes of the metabolic syndrome).
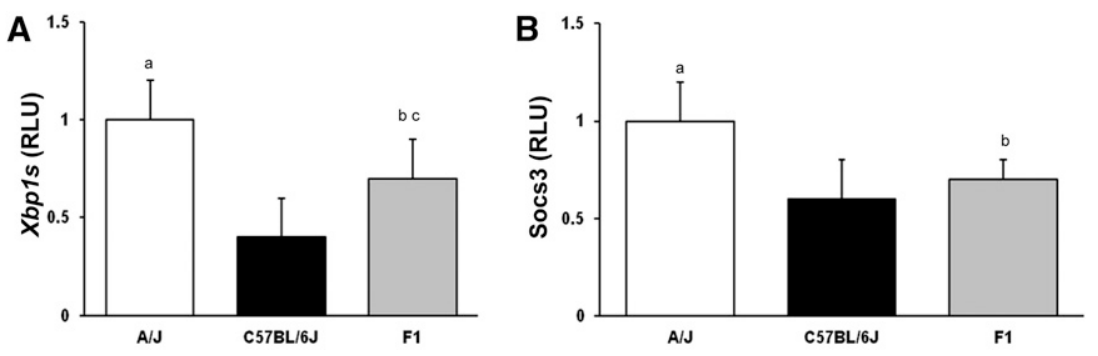

Figure 1 Hepatic mRNA expression of $X b p 1 s$ and Socs3 in $\mathrm{A} / \mathrm{J}, \mathrm{C} 57 \mathrm{BL} / 6$, and $\mathrm{F} 1(\mathrm{~A} / \mathrm{J} \times \mathrm{C} 57 \mathrm{BL} / 6 \mathrm{~J})$ mice. Mice were fed a $60 \%$ high-fat, high-caloric (HFHC) diet for 8 wk and hepatic mRNA expression of (A) Xbp1s and (B) Socs3 measured using RT-PCR. $\mathrm{RLU}$, random light units. Mean $\pm \mathrm{SEM}$. A/J (white), C57BL/6J (black), F1(A/J $\times$ C57BL/6J) (gray) mice; ap $<0.05$ vs. C57BL/6J; bp $<0.05$ vs. A/J mice; $\mathrm{cp}<0.05$ vs. C57BL/6J mice ( $\mathrm{n}=8$ for all groups). 


\section{Identification of eQTLs for hepatic Xbp1s and Socs3 gene expression using $F_{2}(A / J \times C 57 B L / 6 J)$ mice fed a HFHC diet}

Xbp1 and Socs3 are both located on mouse chromosome 11 (Xbp1: 5.5 $\mathrm{Mb}$ and Socs3: 118.0 Mb). We identified an overlapping eQTL for $X b p 1 s$ and Socs 3 on chromosome $1(181.5 \mathrm{Mb})$, with LOD scores of 4.79 and 6.18 , respectively. Additional overlapping eQTLs were also identified on chromosome 11 (56.2 and $58.4 \mathrm{Mb}$ ). There was also an eQTL identified for Socs3 on chromosome 12 (113.4 Mb) with a LOD score of 3.53 (Table 1). Figure 2 and Figure 3 show the whole genome LOD plots and the eQTL linkage maps, respectively. Microarray analysis identified eight and nine differentially expressed candidate genes within the overlapping eQTLs on chromosomes 1 and 11, respectively; five differentially expressed genes were identified in the Socs 3 eQTL on chromosome 12 (Table 2).

\section{Consomic mice replacing A/J Chr 11, but not Chr 1, into C57BL/6J mice reverses the Xbp1s and Socs3 phenotypes}

Because eQTLs for both Xbp1s and Socs3 were identified on chromosomes 1 and 11, we performed RT-PCR of Xbp1s and Socs 3 on hepatic mRNA isolated from C57BL/6J-Chr $1^{\mathrm{A} / J} / \mathrm{NaJ}$ and C57BL/

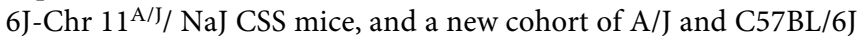
mice, fed the HFHC diet for $8 \mathrm{wk}$. Hepatic gene expression of $\mathrm{Xbp} 1 \mathrm{~s}$ was $1.0 \pm 0.2$ and $0.6 \pm 0.2$ in $\mathrm{A} / \mathrm{J}$ and $\mathrm{C} 57 \mathrm{BL} / 6 \mathrm{~J}-\mathrm{Chr}$ $11^{\mathrm{A} / J} / \mathrm{NaJ}$ mice, and $0.3 \pm 0.2$ and $0.2 \pm 0.2$ in $\mathrm{C} 57 \mathrm{BL} / 6 \mathrm{~J}$ and

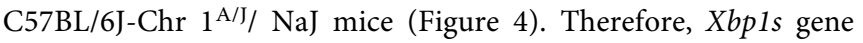
expression was higher in $\mathrm{C} 57 \mathrm{BL} / 6 \mathrm{~J}-\mathrm{Chr} 11^{\mathrm{A} / \mathrm{J} / \mathrm{NaJ}}$ mice than in C57BL6/J mice $(P<0.05)$, but was similar in C57BL/6J-Chr $1^{\mathrm{A} / \mathrm{J} /}$ $\mathrm{NaJ}$ mice and C57BL/6 mice. Replacement of A/J chromosome 11, but not chromosome 1, into strain C57BL/6 mice reversed the Xbp1s phenotype. Hepatic Socs3 gene expression was similar (1.0 \pm 0.2 and $1.0 \pm 0.2 \mathrm{RLU}$ ) in $\mathrm{A} / \mathrm{J}$ and $\mathrm{C} 57 \mathrm{BL} / 6 \mathrm{~J}-\mathrm{Chr} 11^{\mathrm{A} / \mathrm{J} / \mathrm{NaJ}}$ mice, but was also lower in both the C57BL/6J and C57BL/6J-Chr $1^{\mathrm{A} / \mathrm{J} /}$ $\mathrm{NaJ}$ mice, at $0.5 \pm 0.2$ and $0.5 \pm 0.2 \mathrm{RLU}$, respectively $(P<0.05$; $\mathrm{n}=8$ ). Transfer of $\mathrm{A} / \mathrm{J}$ chromosome 11 , but not chromosome 1 , into C57BL/6J mice reversed the Socs3 phenotype, similar to the findings of hepatic Xbp1s mRNA expression.

\section{Identification of QTL for the metabolic syndrome using $F_{2}(A / J \times C 57 B L / 6 J)$ mice fed a HFHC diet}

Table S2 reveals significant differences that were noted between C57BL/6J mice and A/J mice with respect to several metabolic syndrome phenotypes: body weight gain, hepatic triglycerides, fasting serum insulin, fasting serum glucose, and QUICKI, Therefore, we performed QTL analysis with respect to these phenotypes. QTL analysis identified several chromosomal loci associated with body weight gain, fasting serum insulin, and fasting serum glucose; however, no
QTL were identified for the phenotypes of hepatic triglycerides or QUICKI (Table S3).

\section{Identification of eQTLs for hepatic Xbp1 and Socs3 gene expression in the $\mathrm{CCl}_{4}$ model}

To further confirm that the regulation of hepatic Xbp1s and Socs 3 expression is altered in a second animal model of liver injury, we used the carbon tetrachloride $\left(\mathrm{CCl}_{4}\right)$ model of chronic liver injury and fibrogenesis. Wild-type mice fed chow without $\mathrm{CCl}_{4}$ do not develop spontaneous hepatic fibrosis. For this analysis, we searched for coinciding regulatory loci within the Socs 3 and Xbp1 eQTLs on mouse chromosome 1 (164.4-190.5 Mb), chromosome 11 (41.1-73.1 Mb), and chromosome $12(109.9-117.4 \mathrm{Mb})$ in the BXD reference population to allow systematic mapping and integration of multiple complex traits (Andreux et al. 2012). We initially mapped hepatic expression values of Socs 3 and Xbp1s using our microarray-based expression dataset. Figure 5 shows the interval mapping/regression analysis for the phenotype of hepatic Socs 3 expression. The most significant loci were identified on chromosome 1 at $185.2-186.6 \mathrm{Mb}$ for Xbp1 (LOD 3.5; $P_{\mathrm{G}}=0.08$ ) and 193.3-197.1 Mb for Socs3 (LOD 4.4, $P_{\mathrm{G}}=0.01$ ), chromosome 4 at $62.4-68.9 \mathrm{Mb}$ for $X b p 1$ (LOD 3.1, $P_{\mathrm{G}}=0.02$ ), and chromosome 12 at $83.9-89.9 \mathrm{Mb}$ for Socs3 (LOD 5.6; $\left.P_{\mathrm{G}}=0.002\right)$. Of note, the eQTLs for Socs 3 and $X b p 1$ on chromosomes 1 that determine hepatic expression levels after $\mathrm{CCl}_{4}$ challenge coincide with loci that determine gene expression on the HFHC diet as well as eQTLs in control BXD. These findings suggest that baseline expression differences due to genetic variation confer susceptibility to liver injury. Furthermore, the expression differences are inversely correlated with Sirius red-stained collagen areas in livers from $\mathrm{CCl}_{4}$ treated animals $(P<0.001)$ (Hall et al. 2014). We also identified several genes potentially regulated from within the Socs 3 and Xbp1 eQTLs. Table 3 summarizes these cis-regulated differentially expressed genes identified using the BXD lines that co-localize with the eQTLs identified in the HFHC model. Among the regulated genes, only Darc and $Z f p 39$ inherit nsSNPs in coding regions differentiating between C57BL/6J and A/J or DBA/2J mice, respectively.

\section{DISCUSSION}

With the prevalence of NALFD rapidly increasing, it is essential that we gain a better understanding of the pathogenesis and progression of fatty liver disease. Although NAFLD has a hereditary component, the genetics of NAFLD are poorly understood (Schwimmer et al. 2009; Wilfred de Alwis and Day 2008). HFHC diets have been extensively utilized for murine models of obesity, diabetes, and fatty liver. Mice fed this diet develop obesity and many of the components of the metabolic syndrome in a strain-specific manner (Minkina et al. 2012; Jiang et al. 2005; Becker et al. 2004; Schmid et al. 2004; Kobayashi et al. 2004; Rangnekar et al. 2006). In this study, A/J and C57BL/6J

Table 1 Mouse chromosome eQTL locations for Xbp1s and Socs using $F_{2}(A / J \times C 57 B L / 6 J)$ mice

\begin{tabular}{ccccccccccccc}
\hline CHR & Trait & LOD & \multicolumn{1}{c}{ SNP } & Position (Mb) & Interval (Mb) & \# Genes & Diff. SNPs & \multicolumn{1}{c}{$a$} & \multicolumn{1}{c}{$a / S D$} & $d$ & $d / S D$ & $d / a$ \\
\hline 1 & Xbp1s & 4.79 & rs 13476265 & 181.5 & $162.0-183.6$ & 265 & 24,755 & 0.123 & 0.375 & -0.051 & -0.155 & -0.413 \\
1 & Socs3 & 6.18 & rs 13476265 & 181.5 & $172.5-188.7$ & 151 & 14,519 & 0.129 & 0.407 & -0.077 & -0.244 & -0.600 \\
11 & Xbp1s & 3.11 & rs 3684076 & 56.2 & $41.3-73.3$ & 503 & 14,835 & -0.101 & -0.307 & -0.054 & -0.165 & 0.537 \\
11 & Socs3 & 3.09 & rs 3697686 & 58.4 & $44.2-68.8$ & 337 & 11,613 & -0.100 & -0.315 & -0.046 & 60.463 & 0.463 \\
12 & Socs3 & 3.53 & rs 13481655 & 113.4 & $108.7-116.2$ & 79 & 6446 & 0.046 & 0.145 & -0.131 & -0.415 & -2.865 \\
\hline
\end{tabular}

Positive "a" values indicate that at a locus, the homozygous C57BL/6Jt trait mean is greater than the mean of the A/J homozygotes. Negative " $d$ " values indicate that at that locus, the heterozygote trait mean is closer to the A/J homozygote mean than the C57BL/6J homozygote mean. CHR, chromosome; SNP, SNP marker closest to peak LOD score; Interval = 1.0-LOD support interval surrounding the peak LOD score; \# genes = number of protein coding genes within the support interval; Diff. SNPs = number of differential SNPS predicted by MGI in the interval; SD = value in SD units for the trait. Intervals and positions are in megabases (Mb). 
A

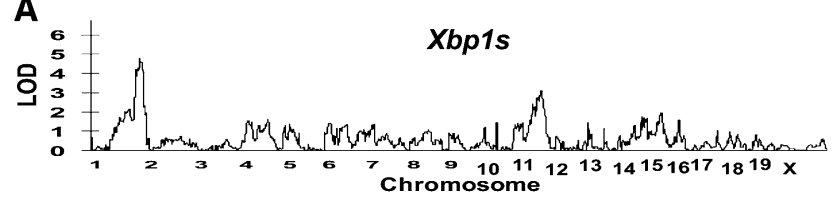

B

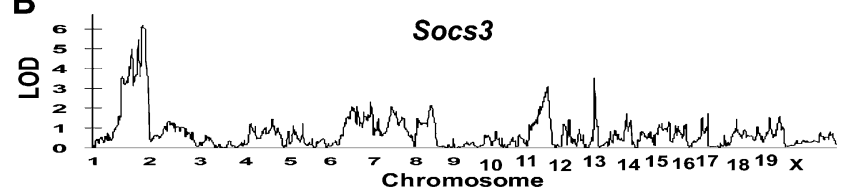

Figure 2 Whole genome LOD plots of eQTLs identified in $A / J$ and C57BL/6J mice fed a high-fat diet.

mice were fed a HFHC diet for 8 wk to identify eQTLs and candidate genes that contribute to NAFLD.

$X b p 1 s$ is a key regulator in the IRE1 $\alpha$ signaling pathway of the unfolded protein response (UPR), which is activated by ER stress. Hepatic ER stress occurs due to insulin resistance, diabetes, obesity, and several liver diseases, including fatty liver, hepatitis $C$, and alpha-1 antitrypsin deficiency (Ji 2008; Lawless et al. 2004; Li et al. 2009; Puri et al. 2008; Malhi and Kaufman 2011). In addition to its role in the UPR, hepatic Xbp1s is an important regulator of fatty acid synthesis and systemic lipid metabolism (Lee et al. 2008; Sha et al. 2009; Ye et al. 2012). Dysregulation of hepatic Xbp1s expression has been shown to be important in the pathogenesis of human NASH (Puri et al. 2008). In addition, several studies have also demonstrated the important role of Socs 3 in the pathogenesis of nonalcoholic steatohepatitis, regulating insulin sensitivity, leptin signaling, glucose metabolism, lipogenesis, and fatty liver (Wang et al. 2009; Ihle 1995; Muraoka et al. 2003; Kievit et al. 2006; Howard et al. 2004; Dittrich et al. 2012; Sachithanandan et al. 2010).

When fed a HFHC diet, hepatic gene expression of both Xbp1s and Socs3 was greater in A/J mice compared with C57BL6/J mice. In contrast, there were no differences in hepatic gene expression of either Xbp1s or Socs3 in chow-fed mice, indicating that the phenotypic change is elicited by feeding the HFHC diet for $8 \mathrm{wk}$. The increased expression of both genes is likely a cellular response to prevent further liver injury, with activation of the unfolded protein response (UPR) and suppression of inflammatory cytokines.

After determining that both hepatic Xbp1s and Socs3 mRNA expression was differentially expressed in HFHC diet-fed A/J and C57BL/6 mice, we applied eQTL analysis to identify genetic loci that may be important in the regulation of these genes that influence the pathogenesis of fatty liver disease. We identified overlapping eQTLs on mouse chromosomes 1 and 11 that were associated with both hepatic Xbp1s and Socs3 expression. We also identified an additional eQTL for Socs3 on chromosome 12. Of note, the murine genes for $X b p 1$ and Socs 3 are located on chromosome 11, although both genes are over $50 \mathrm{Mb}$ away from SNPs rs3684076 and rs3697686 marking the eQTLs. Assuming that a window of $\pm 5 \mathrm{Mb}$ is used to define a cis-QTL, this suggests that they are trans eQTLs (http://www.genenetwork.org/gghelp.html). Using microarray analysis, we identified differentially expressed candidate genes in the overlapping eQTL regions on chromosomes 1 and 11; as well as five additional differentially expressed candidate genes in the Socs 3 eQTL on chromosome 12. No genes that are known to be important in the pathogenesis of nonalcoholic steatohepatitis were identified to be differentially expressed in these loci or the syntenic human loci.

Chromosome substitution strains (CSS) of mice are widely used for gene discovery, genetic and epigenetic studies, functional characterizations, and systems analysis (Singer et al. 2004; Hines et al. 2011).

When C57BL/6J-Chr $11^{\mathrm{A} / J /} \mathrm{NaJ}$ mice were fed a HFHC diet for 8 wk, both hepatic Xbp1s and Socs3 gene expression was similar to A/J mice, yet differed from C57BL/6J mice. In contrast, hepatic Xbp1s or Socs3 gene expression in C57BL/6J-Chr $1^{\mathrm{A} / \mathrm{J} / \mathrm{NaJ}}$ mice remained similar to C57BL/6J mice. This demonstrates that the replacement of the C57BL6/J chromosome 11 with $\mathrm{A} / \mathrm{J}$ chromosome 11 reverses the gene expression phenotype of both Xbp1s and Socs 3 expression from a C57BL/6J to an $\mathrm{A} / \mathrm{J}$ phenotype, supporting the physiologic relevance of the eQTL. Although C57BL/6J-Chr $1^{\mathrm{A} / /} / \mathrm{NaJ}$ and $\mathrm{C} 57 \mathrm{BL} / 6 \mathrm{~J}$ mice had similar hepatic gene expression of Xbp1s and Socs3, it does not exclude the physiologic relevance of the eQTL on chromosome 1 because replacement of the entire chromosome may also change other nonidentified QTL on the chromosome.

We also identified QTL for the phenotypes of serum insulin levels, serum glucose, and weight gain. A QTL on Chr 1 for the phenotype of serum insulin has a small overlapping region with the eQTLs for Xbp1s and Socs3 on Chr 1. We did not identify any QTLs for the phenotypes of hepatic triglycerides or QUICKI. QTLs for murine hepatic triglyceride have been previously reported (Minkina et al. 2012; Lemoine and Serfaty 2012).

C57BL/6J and A/J mice have been commonly used for models of obesity, diabetes, fatty liver, and the metabolic syndrome (Alevizos et al. 2007; Hall et al. 2010; Li et al. 2005; Nishina et al. 1993). Several studies have determined that C57BL/6J are sensitive to and that A/J mice are resistant to metabolic syndrome phenotypes, and our findings are similar to published data. However, human nonalcoholic steatohepatitis (fatty liver with inflammation and fibrosis) is associated with inappropriately low levels of hepatic XBP1 expression compared with bland hepatic steatosis (fatty liver without inflammation and fibrosis) (Puri et al. 2008). Consistent with these data, we have determined that when liver-specific Xbp1-knockout mice in a C57BL/6J background are fed a high-fat/sucrose-fructose diet, they are more susceptible to develop progressive, fibrosing steatohepatitis with less steatosis than flox control mice. Therefore, the hepatic phenotype of the liver-specific Xbp1-null mice is similar to that of C57BL/6J mice, whereas flox controls have a phenotype similar as A/J mice. Socs 3 has also been demonstrated in several studies to be an important mediator of both murine and human NASH (Prpic et al. 2003; Bergen et al. 1999; Parekh et al. 1998; Surwit et al. 1997; Winzell and Ahren 2004; Livingston et al. 1994; Surwit et al. 1988; Tilg 2010; Sachithanandan et al. 2010; Surwit et al. 1995; Watson et al. 2000). Previous studies have also identified other QTL for the metabolic syndrome in mice (Jiang et al. 2005; Rangnekar et al. 2006). In this study, we identified
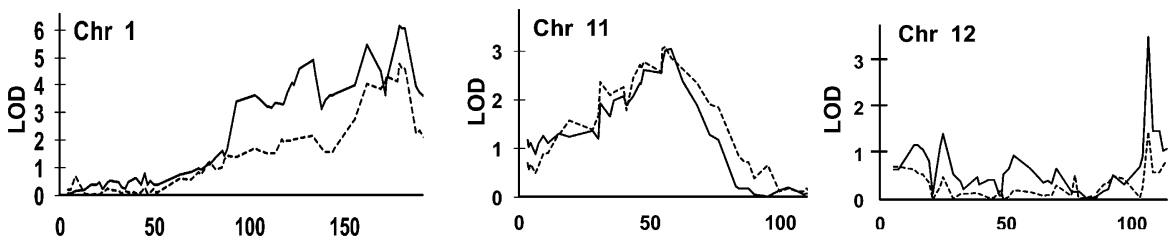

Figure 3 eQTL linkage maps of $A / J$ and C57BL/6J mice fed a high-fat diet. Xbp1s (dashed line). Socs3 (solid line). 
Table 2 Differentially expressed genes from C57BL/6J and A/J mice located within the Xbp1s and Socs3 eQTLs

\begin{tabular}{|c|c|c|c|c|c|c|c|}
\hline & & Gene Name & Entrez ID & $\begin{array}{l}\text { Average } \\
\text { Expression }\end{array}$ & $P$ & SNP & nsSNP \\
\hline \multirow[t]{15}{*}{ Chr 1} & Apcs & Serum amyloid P-component & 20219 & 13.12 & $4.58 \mathrm{E}-23$ & 4 & 0 \\
\hline & Darc & Duffy blood group, chemokine receptor & 13349 & 8.73 & $1.88 \mathrm{E}-13$ & 0 & 0 \\
\hline & Dusp23 & Dual specificity phosphatase 23 & 68440 & 10.02 & 4.40E-12 & 38 & 0 \\
\hline & Ephx & Epoxide hydrolase 1, microsomal & 13849 & 13.18 & $1.07 \mathrm{E}-04$ & 52 & 0 \\
\hline & F11 $r$ & F11 receptor & 16456 & 9.52 & $1.03 \mathrm{E}-18$ & 112 & 0 \\
\hline & Fcer1g & Fc receptor, IgE, high affinity I,polypeptide & 14127 & 8.53 & $1.35 \mathrm{E}-30$ & 39 & 0 \\
\hline & Fmo3 & Flavin containing monooxygenase 3 & 14262 & 11.23 & 2.04E-08 & 4 & 0 \\
\hline & Gm5561 & Predicted gene 5561 & 433941 & 11.19 & $3.03 E-12$ & 0 & 0 \\
\hline & Mgst3 & Microsomal glutathione S-transferase 3 & 66447 & 11.02 & $1.60 \mathrm{E}-03$ & 0 & 0 \\
\hline & Pex19 & Peroxisomal biogenesis factor 19 & 19298 & 12.31 & $7.24 \mathrm{E}-11$ & 65 & 1 \\
\hline & Psen2 & Presenilin 2 & 19165 & 10.9 & $9.43 \mathrm{E}-18$ & 31 & 0 \\
\hline & Rgs4 & Regulator of G-protein signaling 4 & 19736 & 8.88 & $1.41 \mathrm{E}-06$ & 25 & 0 \\
\hline & Srp9 & Signal recognition particle 9 & 27058 & 9.61 & $1.29 \mathrm{E}-14$ & 28 & 0 \\
\hline & Susd4 & Sushi domain containing 4 & 96935 & 9.05 & 4.36E-05 & 10 & 0 \\
\hline & Uap1 & UDP-N-acetylglucosamine pyrophosphorylase 1 & 107652 & 9.5 & $1.47 \mathrm{E}-16$ & 28 & 0 \\
\hline \multirow[t]{9}{*}{ Chr 11} & Atox1 & ATX1 (antioxidant protein 1) homolog 1 (yeast) & 11927 & 12.24 & 2.06E-13 & 0 & 0 \\
\hline & Dhrs1 & Dehydrogenase/reductase (SDR family) member 1 & 52585 & 12.1 & 7.32E-11 & 0 & 0 \\
\hline & lgtp & Interferon gamma induced GTPase & 16145 & 11.05 & 2.70E-07 & 23 & 2 \\
\hline & Pemt & Phosphatidylethanolamine $\mathrm{N}$-methyltransferase & 18618 & 13.15 & $1.72 \mathrm{E}-09$ & 30 & 0 \\
\hline & Snap47 & Synaptosomal-associated protein, 47 & 67826 & 8.89 & $1.30 \mathrm{E}-14$ & 6 & 0 \\
\hline & Timd2 & T-cell immunoglobulin and mucin domain containing 2 & 171284 & 12.74 & 1.49E-18 & 41 & 0 \\
\hline & Timd4 & T-cell immunoglobulin and mucin domain containing 4 & 276891 & 8.87 & 2.88E-08 & 49 & 2 \\
\hline & Trim11 & Tripartite motif-containing 11 & 94091 & 8.32 & 8.34E-28 & 30 & 0 \\
\hline & Zfp39 & Zinc finger protein 39 & 22698 & 8.44 & $9.31 \mathrm{E}-16$ & 33 & 2 \\
\hline \multirow[t]{5}{*}{ Chr 12} & Adssl1 & Adenylosuccinate synthetase like 1 & 111565 & 11.62 & $6.94 \mathrm{E}-13$ & 56 & 0 \\
\hline & Amn & Amnionless & 93835 & 8.42 & $1.56 \mathrm{E}-13$ & 7 & 1 \\
\hline & AW555464 & Expressed sequence AW555464 & 217882 & 11.28 & $1.24 \mathrm{E}-15$ & 43 & 2 \\
\hline & $\mathrm{Ckb}$ & Creatine kinase, brain & 12709 & 9.81 & 8.69E-05 & 7 & 0 \\
\hline & Ppp1r13b & Protein phosphatase 1 , regulatory subunit $13 \mathrm{~B}$ & 21981 & 8.89 & $9.16 \mathrm{E}-13$ & 98 & 0 \\
\hline
\end{tabular}

Differentially expressed genes in the eQTLs. The genes on Chr 1 and Chr 11 are in both the Xbp1s and Socs3 eQTL. The genes on Chr 12 are in a Socs3 eQTL. SNP, differential SNPs between strains; nsSNP, nsSNPs differential SNPs.

14 QTL that are related to metabolic syndrome phenotypes, but we did not identify QTL for hepatic triglycerides.

To determine whether the identified regulatory eQTLs for Xbp1s and Socs 3 may be important in other forms of liver injury, we used the $\mathrm{CCl}_{4}$ model of hepatotoxicity and fibrosis using the BXD lines as an established murine reference panel for systems genetics (Andreux et al. 2012). eQTL analysis was performed in $\mathrm{F}_{2}(\mathrm{~A} / \mathrm{J} \times \mathrm{C} 57 \mathrm{BL} / 6 \mathrm{~J})$ mice because feeding a HFHC diet to $\mathrm{A} / \mathrm{J}$ and $\mathrm{C} 57 \mathrm{BL} / 6 \mathrm{~J}$ mice is a wellestablished model for genetic and physiologic studies of the metabolic syndrome. The BXD lines, however, provided an efficient murine model for the experiments administering $\mathrm{CCl}_{4}$. In this second model of liver injury, we identified significant regulatory loci for Socs 3 and Xbp1s expression on chromosomes 1 and 12, including an overlapping region on chromosome 1 that is influenced by the parental C57BL/6J allele in both experimental crosses.

A GWAS study of the Dallas Heart study population has revealed that a polymorphism of PNPLA3 (rs738409; I148M) is strongly associated with increased hepatic fat levels and susceptibility to nonalcoholic fatty liver disease (Romeo et al. 2008). This polymorphism has subsequently been associated with the severity of NASH, liver stiffness, fibrosis, and potentially hepatocellular carcinoma. Overexpression of the PNPLA3 I148M polymorphism in mice also causes hepatic steatosis and PNPLA3 has been shown to regulate hepatic lipid metabolism (Basantani et al. 2011; Chen et al. 2010; Li et al. 2012; Ruhanen et al. 2014; Singal et al. 2014; Said 2013; Pingitore et al. 2014; Krawczyk et al. 2013; Peng et al. 2012; Santoro et al. 2010; Rotman et al.
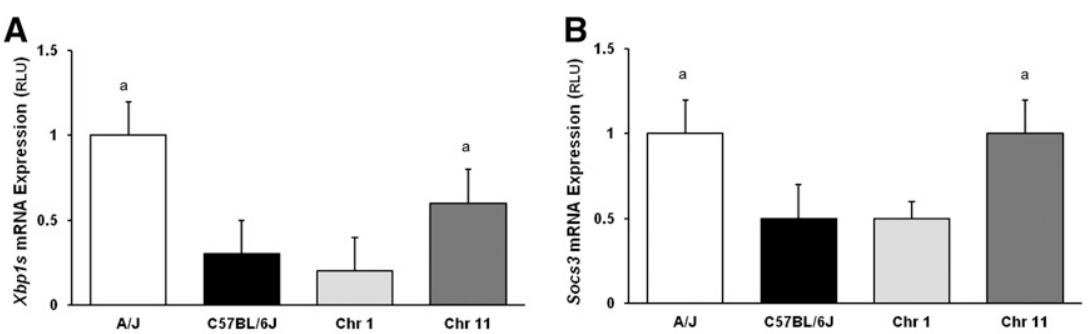

Figure 4 Hepatic mRNA expression of Xbp1s and Socs3 in $\mathrm{A} / \mathrm{J}, \mathrm{C} 57 \mathrm{BL} / 6 \mathrm{~J}$, and $\mathrm{C} 57 \mathrm{BL} / 6 \mathrm{~J}-\mathrm{Chr} 1 \mathrm{~A} / \mathrm{J} /$ $\mathrm{NaJ}$ and $\mathrm{C} 57 \mathrm{BL} / 6 \mathrm{~J}-\mathrm{Chr} 11 \mathrm{~A} / \mathrm{J} / \mathrm{NaJ}$ mice. Male $\mathrm{A} / \mathrm{J}$, C57BL/6J, C57BL/6J-Chr 1A/J/NaJ, and C57BL/6JChr $11 \mathrm{~A} / \mathrm{J} / \mathrm{NaJ}$ mice were fed a $60 \%$ high-fat, highcaloric (HFHC) diet for $8 \mathrm{wk}$ and hepatic mRNA expression of (A) Xbp1s and (B) Socs3 gene expression measured using RT-PCR. RLU, random light units. Mean \pm SEM. A/J (white), C57BL/6J (black), C57BL/6J-Chr 1A/J/NaJ (Chr 1, light gray), and C57BL/6J-Chr 11A/J/NaJ (Chr 11, dark gray). ap < 0.05 vs. both $\mathrm{C} 57 \mathrm{BL} / 6 \mathrm{~J}$ and $\mathrm{C} 57 \mathrm{BL} / 6 \mathrm{~J}-\mathrm{Chr} 1 \mathrm{~A} / \mathrm{J} /$ $\mathrm{NaJ}$ mice $(\mathrm{n}=8)$. 


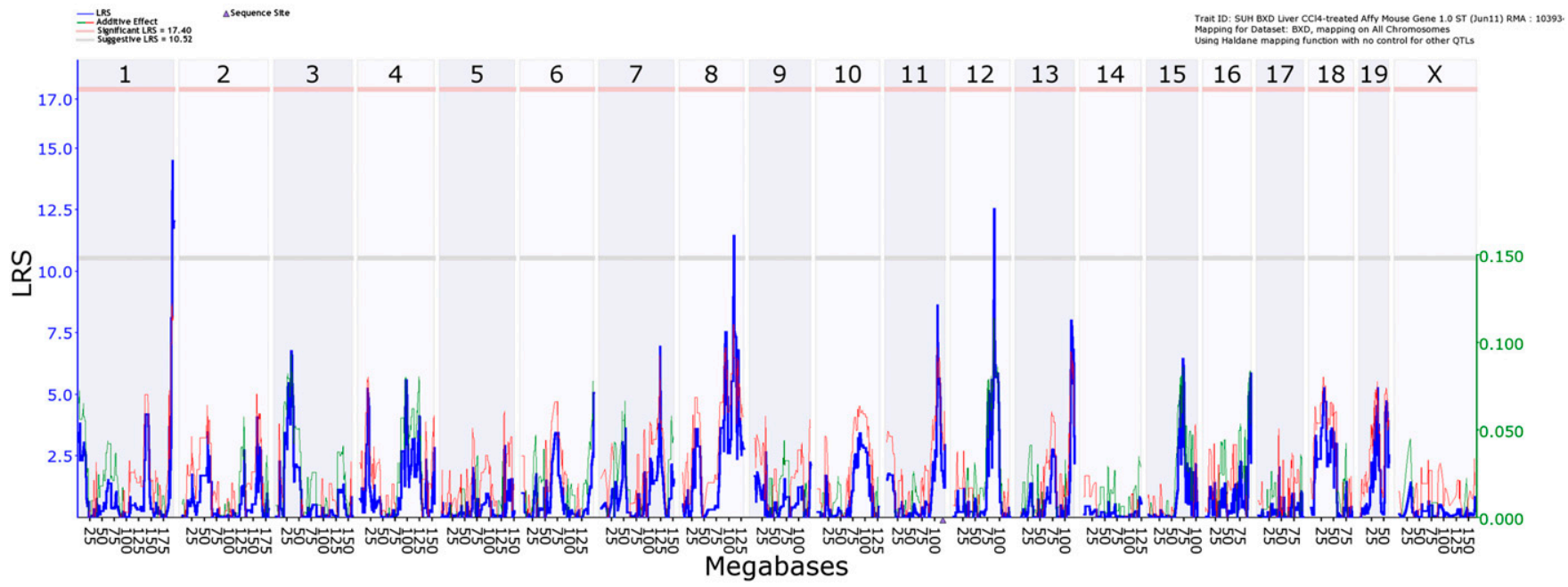

Figure 5 Interval mapping/regression analysis of BXD mice treated with carbon tetrachloride (CCI4). Chow-fed BXD murine lines were treated with $\mathrm{CCl} 4$ and Socs3 hepatic gene expression was measured. eQTLs were identified using interval mapping as implemented in GeneNetwork.

2010; Speliotes et al. 2010; Zain et al. 2012). Therefore, increasing evidence indicates that PNPLA3 polymorphisms have an important role in hepatic lipid metabolism and human fatty liver disorders. A TM6SF2 variant confers susceptibility to human nonalcoholic fatty liver disease, as well as influences total cholesterol and myocardial infarction risk (Kozlitina et al. 2014; Holmen et al. 2014; Glimcher and Lee 2009). Recent data also demonstrate that UDP-galactose4 -epimerase (GalE) is a direct transcriptional target of Xbp1s that is located at $136 \mathrm{Mb}$ on chromosome 4 within our QTL interval for weight gain. Several SNPs, including rs2645424, rs343062, SNP rs1227756, rs6591182, rs887304, rs2499604, rs6487679, rs1421201, and rs2710833, have been associated with NAFLD, NASH, or serum aminotransferase elevation (Chalasani et al. 2010; Kilpelainen et al. 2011). Significant associations with histologic NAFLD have also been identified at variants in or near NCAN, GCKR, and LYPLAL1 (Speliotes et al. 2011). The roles of these SNPs in fatty liver diseases and lipid metabolism require further investigation.
Hepatic Xbp1s is induced by the endoplasmic reticulum stress that occurs in viral hepatitis, alpha- 1 antitrypsin deficiency, obesity, insulin resistance, and hepatic steatosis. Xbp1s is formed by an atypical splice mechanism in which the endonuclease IRE-12 excises 26 nucleotides from the unspliced $X b p 1$ and causes a frame shift that removes an early stop codon. Socs 3 is a negative regulator of cytokine signaling, with expression induced by cytokines such as interferon- $\gamma$, interleukin6 , and interleukin-10. None of the candidate genes that we identified are known to regulate Xbp1s or Socs3, nor have they previously been associated with the pathogenesis of fatty liver.

Human NAFLD is a highly prevalent disease that is closely associated with the metabolic syndrome, although the pathogenesis remains poorly understood. Several studies have shown that genetic factors are important in the pathogenesis of fatty liver; however, many of the specific genetic factors remain unknown. In this study, we have identified overlapping eQTLs for the phenotypes of Xbp1s and Socs3 expression levels, genes that are likely important in the pathogenesis of

Table 3 Differentially expressed hepatic genes identified in Xbp1s and Socs3 eQTLs regions that are cis-regulated in BXD mice treated with $\mathrm{CCl}_{4}$

\begin{tabular}{|c|c|c|c|c|c|c|c|c|c|c|c|}
\hline \multicolumn{4}{|c|}{ eQTL (BXD) } & \multirow[b]{2}{*}{$\begin{array}{c}\text { Cis-Regulated Genes } \\
\text { (Gene ID) }\end{array}$} & \multirow{2}{*}{$\begin{array}{l}\text { Gene } \\
\text { Location } \\
\text { (Mb) }\end{array}$} & \multirow{2}{*}{$\begin{array}{c}\text { Mean } \\
\text { Hepatic } \\
\text { mRNA } \\
\text { Expression }\end{array}$} & \multirow[b]{2}{*}{$\begin{array}{l}\text { Max. } \\
\text { LOD }\end{array}$} & \multirow{2}{*}{$\begin{array}{l}\text { Max. LOD } \\
\text { Location } \\
\text { (Chr:Mb) }\end{array}$} & \multicolumn{3}{|c|}{ nsSNP Variants } \\
\hline Chr & Trait & $\begin{array}{l}\text { Location } \\
\text { (Mb) }\end{array}$ & $\begin{array}{l}\text { Allele } \\
\text { Effect }^{a}\end{array}$ & & & & & & B & $\mathrm{D}$ & $A / J$ \\
\hline \multirow{4}{*}{1} & & & & $\begin{array}{l}\text { Pex19: Peroxisomal biogenesis } \\
\text { factor } 19 \text { (19298) }\end{array}$ & 174.1 & 11.2 & 2.4 & Chr1: 125.0 & & & \\
\hline & Xbp1 & $186.2-186.6$ & $-0.102(B)$ & $\begin{array}{l}\text { Apcs: Serum amyloid } \\
\text { P-component (20219) }\end{array}$ & 174.8 & 12.0 & 7.5 & Chr1: 173.0 & \multirow{3}{*}{ A } & \multirow{3}{*}{ G } & \multirow{3}{*}{ G } \\
\hline & & & & $\begin{array}{l}\text { Darc: Duffy blood group, } \\
\text { chemokine receptor (13349) }\end{array}$ & 175.3 & 8.5 & 5.4 & Chr1: 174.2 & & & \\
\hline & & & & Psen2: Presenilin 2 (19165) & 182.2 & 10.8 & 4.3 & Chr1: 182.2 & & & \\
\hline 11 & Socs3 & $106.5-106.8$ & $-0.097(B)$ & $\begin{array}{l}\text { Zfp39: Zinc finger protein } 39 \\
\text { (22698) }\end{array}$ & 58.7 & 8.7 & 10.6 & Chr11: 58.9 & $A$ & G & G \\
\hline
\end{tabular}

\footnotetext{
${ }^{a}$ Allele effects are estimated change in trait mean (gene expression) by replacement of one allele by the other: negative values indicate that higher expression values
} are produced by the $\mathrm{C} 57 \mathrm{BL} / 6 \mathrm{~J}(\mathrm{~B})$ allele and positive values by $\mathrm{DBA} / 2 \mathrm{~J}(\mathrm{D})$ allele. 
fatty liver disorders. We have also used microarray analysis to identify differentially expressed candidate genes in the eQTL regions. Future studies using fine-mapping techniques, positional cloning, or genetically altered mice may identify the genes or polymorphisms that are responsible for disease expression. Given the increasing prevalence of NAFLD, it is essential that we further understand the genetics and pathophysiology of fatty liver diseases so that we can develop rationale therapeutic options for this common liver disease.

\section{LITERATURE CITED}

Alevizos, I., J. Misra, J. Bullen, G. Basso, J. Kelleher et al., 2007 Linking hepatic transcriptional changes to high-fat diet induced physiology for diabetes-prone and obese-resistant mice. Cell Cycle 6: 1631-1638.

Andreux, P. A., E. G. Williams, H. Koutnikova, R. H. Houtkooper, M. F. Champy et al., 2012 Systems genetics of metabolism: the use of the BXD murine reference panel for multiscalar integration of traits. Cell 150: $1287-1299$.

Angulo, P., 2002 Nonalcoholic fatty liver disease. N. Engl. J. Med. 346: 1221-1231.

Basantani, M. K., M. T. Sitnick, L. Cai, D. S. Brenner, N. P. Gardner et al., 2011 Pnpla3/Adiponutrin deficiency in mice does not contribute to fatty liver disease or metabolic syndrome. J. Lipid Res. 52: 318-329.

Becker, W., R. Kluge, T. Kantner, K. Linnartz, M. Korn et al., 2004 Differential hepatic gene expression in a polygenic mouse model with insulin resistance and hyperglycemia: evidence for a combined transcriptional dysregulation of gluconeogenesis and fatty acid synthesis. J. Mol. Endocrinol. 32: 195-208.

Bergen, H. T., T. Mizuno, J. Taylor, and C. V. Mobbs, 1999 Resistance to diet-induced obesity is associated with increased proopiomelanocortin mRNA and decreased neuropeptide Y mRNA in the hypothalamus. Brain Res. 851: 198-203.

Bolstad, B. M., R. A. Irizarry, M. Astrand, and T. P. Speed, 2003 A comparison of normalization methods for high density oligonucleotide array data based on variance and bias. Bioinformatics 19: 185-193.

Brenner, C., L. Galluzzi, O. Kepp, and G. Kroemer, 2013 Decoding cell death signals in liver inflammation. J. Hepatol. 59: 583-594.

Broman, K. W., H. Wu, S. Sen, and G. A. Churchill, 2003 R/qtl: QTL mapping in experimental crosses. Bioinformatics 19: 889-890.

Browning, J. D., and J. D. Horton, 2004 Molecular mediators of hepatic steatosis and liver injury. J. Clin. Invest. 114: 147-152.

Chalasani, N., X. Guo, R. Loomba, M.O. Goodarzi, T. Haritunians et al., 2010 Genome-wide association study identifies variants associated with histologic features of nonalcoholic fatty liver disease. Gastroenterology 139:1567-1576, 1576.e1-6.

Chen, L., and J. D. Storey, 2006 Relaxed significance criteria for linkage analysis. Genetics 173: 2371-2381.

Chen, W., B. Chang, L. Li, and L. Chan, 2010 Patatin-like phospholipase domain-containing 3/adiponutrin deficiency in mice is not associated with fatty liver disease. Hepatology 52: 1134-1142.

Clementi, A. H., A. M. Gaudy, N. van Rooijen, R. H. Pierce, and R. A. Mooney, 2009 Loss of Kupffer cells in diet-induced obesity is associated with increased hepatic steatosis, STAT3 signaling, and further decreases in insulin signaling. Biochim. Biophys. Acta 1792: 1062-1072.

Cnop, M., F. Foufelle, and L. A. Velloso, 2012 Endoplasmic reticulum stress, obesity and diabetes. Trends Mol. Med. 18: 59-68.

Dittrich, A., C. Khouri, S. D. Sackett, C. Ehlting, O. Bohmer et al., 2012 Glucocorticoids increase interleukin-6-dependent gene induction by interfering with the expression of the suppressor of cytokine signaling 3 feedback inhibitor. Hepatology 55: 256-266.

Eizirik, D. L., A. K. Cardozo, and M. Cnop, 2008 The role for endoplasmic reticulum stress in diabetes mellitus. Endocr. Rev. 29: 42-61.

Fullerton, J., M. Cubin, H. Tiwari, C. Wang, A. Bomhra et al., 2003 Linkage analysis of extremely discordant and concordant sibling pairs identifies quantitative-trait loci that influence variation in the human personality trait neuroticism. Am. J. Hum. Genet. 72: 879-890.
Glimcher, L. H., and A. H. Lee, 2009 From sugar to fat: How the transcription factor XBP1 regulates hepatic lipogenesis. Ann. N. Y. Acad. Sci. 1173(Suppl 1): E2-E9.

Hall, D., C. Poussin, V. R. Velagapudi, C. Empsen, M. Joffraud et al., 2010 Peroxisomal and microsomal lipid pathways associated with resistance to hepatic steatosis and reduced pro-inflammatory state. J. Biol. Chem. 285: 31011-31023.

Hall, R. A., R. Liebe, K. Hochrath, A. Kazakov, R. Alberts et al., 2014 Systems genetics of liver fibrosis: identification of fibrogenic and expression quantitative trait loci in the BXD murine reference population. PLoS ONE 9: e89279.

Handy, J. A., P. P. Fu, P. Kumar, J. E. Mells, S. Sharma et al., 2011 Adiponectin inhibits leptin signalling via multiple mechanisms to exert protective effects against hepatic fibrosis. Biochem. J. 440: 385-395.

Hines, I. N., H. J. Hartwell, Y. Feng, E. J. Theve, G. A. Hall et al., 2011 Insulin resistance and metabolic hepatocarcinogenesis with parent-of-origin effects in AxB mice. Am. J. Pathol. 179: 2855-2865.

Holmen, O. L., H. Zhang, Y. Fan, D. H. Hovelson, E. M. Schmidt et al., 2014 Systematic evaluation of coding variation identifies a candidate causal variant in TM6SF2 influencing total cholesterol and myocardial infarction risk. Nat. Genet. 46: 345-351.

Howard, J. K., B. J. Cave, L. J. Oksanen, I. Tzameli, C. Bjorbaek et al., 2004 Enhanced leptin sensitivity and attenuation of diet-induced obesity in mice with haploinsufficiency of Socs3. Nat. Med. 10: 734-738.

Ihle, J. N., 1995 Cytokine receptor signalling. Nature 377: 591-594.

Ji, C., 2008 Dissection of endoplasmic reticulum stress signaling in alcoholic and non-alcoholic liver injury. J. Gastroenterol. Hepatol. 23(Suppl 1): S16-S24.

Ji, C., and N. Kaplowitz, 2006 ER stress: can the liver cope? J. Hepatol. 45: 321-333.

Jiang, T., Z. Wang, G. Proctor, S. Moskowitz, S. E. Liebman et al., 2005 Diet-induced obesity in C57BL/6J mice causes increased renal lipid accumulation and glomerulosclerosis via a sterol regulatory elementbinding protein-1c-dependent pathway. J. Biol. Chem. 280: 32317-32325.

Kaser, A., A. H. Lee, A. Franke, J. N. Glickman, S. Zeissig et al., 2008 XBP1 links ER stress to intestinal inflammation and confers genetic risk for human inflammatory bowel disease. Cell 134: 743-756.

Kievit, P., J. K. Howard, M. K. Badman, N. Balthasar, R. Coppari et al., 2006 Enhanced leptin sensitivity and improved glucose homeostasis in mice lacking suppressor of cytokine signaling-3 in POMC-expressing cells. Cell Metab. 4: 123-132.

Kilpelainen, T. O., M. C. Zillikens, A. Stancakova, F. M. Finucane, J. S. Ried et al., 2011 Genetic variation near IRS1 associates with reduced adiposity and an impaired metabolic profile. Nat. Genet. 43: 753-760.

Kobayashi, M., T. Ohno, T. Tsuchiya, and F. Horio, 2004 Characterization of diabetes-related traits in MSM and JF1 mice on high-fat diet. J. Nutr. Biochem. 15: 614-621.

Kozlitina, J., E. Smagris, S. Stender, B. G. Nordestgaard, H. H. Zhou et al., 2014 Exome-wide association study identifies a TM6SF2 variant that confers susceptibility to nonalcoholic fatty liver disease. Nat. Genet. 46: 352-356.

Krawczyk, M., F. Grunhage, and F. Lammert, 2013 Identification of combined genetic determinants of liver stiffness within the SREBP1cPNPLA3 pathway. Int. J. Mol. Sci. 14: 21153-21166.

Lawless, M. W., C. M. Greene, A. Mulgrew, C. C. Taggart, S. J. O’Neill et al., 2004 Activation of endoplasmic reticulum-specific stress responses associated with the conformational disease $\mathrm{Z}$ alpha 1-antitrypsin deficiency. J. Immunol. 172: 5722-5726.

Lazo, M., and J. M. Clark, 2008 The epidemiology of nonalcoholic fatty liver disease: a global perspective. Semin. Liver Dis. 28: 339-350.

Lee, A. H., E. F. Scapa, D. E. Cohen, and L. H. Glimcher, 2008 Regulation of hepatic lipogenesis by the transcription factor XBP1. Science 320: 14921496.

Lemoine, M., and L. Serfaty, 2012 [Nonalcoholic fatty liver disease] Presse Med. 41: 169-189.

Li, J., and L. Ji, 2005 Adjusting multiple testing in multilocus analyses using the eigenvalues of a correlation matrix. Heredity (Edinb) 95: 221-227. 
Li, Z., M. J. Soloski, and A. M. Diehl, 2005 Dietary factors alter hepatic innate immune system in mice with nonalcoholic fatty liver disease. Hepatology 42: 880-885.

Li, S., L. Ye, X. Yu, B. Xu, K. Li et al., 2009 Hepatitis C virus NS4B induces unfolded protein response and endoplasmic reticulum overload responsedependent NF-kappaB activation. Virology 391: 257-264.

Li, J. Z., Y. Huang, R. Karaman, P. T. Ivanova, H. A. Brown et al., 2012 Chronic overexpression of PNPLA3I148M in mouse liver causes hepatic steatosis. J. Clin. Invest. 122: 4130-4144.

Livingston, E. G., M. N. Feinglos, C. M. Kuhn, C. Secor, and R. S. Surwit, 1994 Hyperinsulinemia in the pregnant C57BL/6J mouse. Horm. Metab. Res. 26: 307-308.

Malhi, H., and R. J. Kaufman, 2011 Endoplasmic reticulum stress in liver disease. J. Hepatol. 54: 795-809.

Minkina, O., J.M. Cheverud, G. Fawcett, C.F. Semenkovich, and J.P. KenneyHunt, 2012 Quantitative trait loci affecting liver fat content in mice. G3 (Bethesda) 2:1019-1025.

Moschen, A. R., C. Molnar, S. Geiger, I. Graziadei, C. F. Ebenbichler et al., 2010 Anti-inflammatory effects of excessive weight loss: potent suppression of adipose interleukin 6 and tumour necrosis factor alpha expression. Gut 59: 1259-1264.

Mu, J. L., J. K. Naggert, K. L. Svenson, G. B. Collin, J. H. Kim et al., 1999 Quantitative trait loci analysis for the differences in susceptibility to atherosclerosis and diabetes between inbred mouse strains C57BL/6J and C57BLKS/J. J. Lipid Res. 40: 1328-1335.

Muraoka, O., B. Xu, T. Tsurumaki, S. Akira, T. Yamaguchi et al., 2003 Leptininduced transactivation of NPY gene promoter mediated by JAK1, JAK2 and STAT3 in the neural cell lines. Neurochem. Int. 42: 591-601.

Nishina, P. M., J. Wang, W. Toyofuku, F. A. Kuypers, B. Y. Ishida et al., 1993 Atherosclerosis and plasma and liver lipids in nine inbred strains of mice. Lipids 28: 599-605.

Ogawa, W., and M. Kasuga, 2008 Cell signaling. Fat stress and liver resistance. Science 322: 1483-1484.

Ong, J. P., A. Pitts, and Z. M. Younossi, 2008 Increased overall mortality and liver-related mortality in non-alcoholic fatty liver disease. J. Hepatol. 49: 608-612.

Parekh, P. I., A. E. Petro, J. M. Tiller, M. N. Feinglos, and R. S. Surwit, 1998 Reversal of diet-induced obesity and diabetes in C57BL/6J mice. Metabolism 47: 1089-1096.

Paterson, A. H., S. Damon, J. D. Hewitt, D. Zamir, H. D. Rabinowitch et al., 1991 Mendelian factors underlying quantitative traits in tomato: comparison across species, generations, and environments. Genetics 127: 181-197.

Peng, X. E., Y. L. Wu, S. W. Lin, Q. Q. Lu, Z. J. Hu et al., 2012 Genetic variants in PNPLA3 and risk of non-alcoholic fatty liver disease in a Han Chinese population. PLoS ONE 7: e50256.

Pingitore, P., C. Pirazzi, R. M. Mancina, B. M. Motta, C. Indiveri et al., 2014 Recombinant PNPLA3 protein shows triglyceride hydrolase activity and its I148M mutation results in loss of function. Biochim. Biophys. Acta 1841: 574-580.

Pomp, D., 1997 Genetic dissection of obesity in polygenic animal models. Behav. Genet. 27: 285-306.

Prpic, V., P. M. Watson, I. C. Frampton, M. A. Sabol, G. E. Jezek et al., 2003 Differential mechanisms and development of leptin resistance in A/J vs. C57BL/6J mice during diet-induced obesity. Endocrinology 144: $1155-1163$.

Puri, P., F. Mirshahi, O. Cheung, R. Natarajan, J. W. Maher et al., 2008 Activation and dysregulation of the unfolded protein response in nonalcoholic fatty liver disease. Gastroenterology 134: 568-576.

Rangnekar, A. S., F. Lammert, A. Igolnikov, and R. M. Green, 2006 Quantitative trait loci analysis of mice administered the methioninecholine deficient dietary model of experimental steatohepatitis. Liver Int. 26: $1000-1005$.

Rapp, J. P., 2000 Genetic analysis of inherited hypertension in the rat. Physiol. Rev. 80: 135-172.

Reid, A. E., 2001 Nonalcoholic steatohepatitis. Gastroenterology 121: 710723.
Romeo, S., J. Kozlitina, C. Xing, A. Pertsemlidis, D. Cox et al., 2008 Genetic variation in PNPLA3 confers susceptibility to nonalcoholic fatty liver disease. Nat. Genet. 40: 1461-1465.

Ron, D., and P. Walter, 2007 Signal integration in the endoplasmic reticulum unfolded protein response. Nat. Rev. Mol. Cell Biol. 8: 519529.

Rotman, Y., C. Koh, J. M. Zmuda, D. E. Kleiner, and T. J. Liang, 2010 The association of genetic variability in patatin-like phospholipase domaincontaining protein 3 (PNPLA3) with histological severity of nonalcoholic fatty liver disease. Hepatology 52: 894-903.

Ruhanen, H., J. Perttila, M. Holtta-Vuori, Y. Zhou, H. Yki-Jarvinen et al., 2014 PNPLA3 mediates hepatocyte triacylglycerol remodeling. J. Lipid Res. 55: 739-746.

Sachithanandan, N., B. C. Fam, S. Fynch, N. Dzamko, M. J. Watt et al., 2010 Liver-specific suppressor of cytokine signaling-3 deletion in mice enhances hepatic insulin sensitivity and lipogenesis resulting in fatty liver and obesity. Hepatology 52: 1632-1642.

Said, A., 2013 Non-alcoholic fatty liver disease and liver transplantation: outcomes and advances. World J. Gastroenterol. 19: 9146-9155.

Santoro, N., R. Kursawe, E. D’Adamo, D. J. Dykas, C. K. Zhang et al., 2010 A common variant in the patatin-like phospholipase 3 gene (PNPLA3) is associated with fatty liver disease in obese children and adolescents. Hepatology 52: 1281-1290.

Schmid, G. M., V. Converset, N. Walter, M. V. Sennitt, K. Y. Leung et al., 2004 Effect of high-fat diet on the expression of proteins in muscle, adipose tissues, and liver of C57BL/6 mice. Proteomics 4: 2270-2282.

Schwimmer, J. B., M. A. Celedon, J. E. Lavine, R. Salem, N. Campbell et al., 2009 Heritability of nonalcoholic fatty liver disease. Gastroenterology 136: 1585-1592.

Sha, H., Y. He, H. Chen, C. Wang, A. Zenno et al., 2009 The IRE1alpha$\mathrm{XBP} 1$ pathway of the unfolded protein response is required for adipogenesis. Cell Metab. 9: 556-564.

Silverman, J. F., W. J. Pories, and J. F. Caro, 1989 Liver pathology in diabetes mellitus and morbid obesity. Clinical, pathological, and biochemical considerations. Pathol. Annu. 24(Pt 1): 275-302.

Singal, A. G., H. Manjunath, A. C. Yopp, M. S. Beg, J. A. Marrero et al., 2014 The effect of PNPLA3 on fibrosis progression and development of hepatocellular carcinoma: a meta-analysis. Am. J. Gastroenterol. 109: 325-334.

Singer, J. B., A. E. Hill, L. C. Burrage, K. R. Olszens, J. Song et al., 2004 Genetic dissection of complex traits with chromosome substitution strains of mice. Science 304: 445-448.

Speliotes, E. K., J. M. Massaro, U. Hoffmann, M. C. Foster, D. V. Sahani et al., 2008 Liver fat is reproducibly measured using computed tomography in the Framingham Heart Study. J. Gastroenterol. Hepatol. 23: 894-899.

Speliotes, E. K., J. M. Massaro, U. Hoffmann, R. S. Vasan, J. B. Meigs et al., 2010 Fatty liver is associated with dyslipidemia and dysglycemia independent of visceral fat: the Framingham Heart Study. Hepatology 51: 1979-1987.

Speliotes, E. K., L. M. Yerges-Armstrong, J. Wu, R. Hernaez, L. J. Kim et al., 2011 Genome-wide association analysis identifies variants associated with nonalcoholic fatty liver disease that have distinct effects on metabolic traits. PLoS Genet. 7: e1001324.

Surwit, R. S., C. M. Kuhn, C. Cochrane, J. A. McCubbin, and M. N. Feinglos, 1988 Diet-induced type II diabetes in C57BL/6J mice. Diabetes 37: 1163-1167.

Surwit, R. S., M. N. Feinglos, J. Rodin, A. Sutherland, A. E. Petro et al., 1995 Differential effects of fat and sucrose on the development of obesity and diabetes in C57BL/6J and A/J mice. Metabolism 44: 645-651.

Surwit, R. S., A. E. Petro, P. Parekh, and S. Collins, 1997 Low plasma leptin in response to dietary fat in diabetes- and obesity-prone mice. Diabetes 46: 1516-1520.

Tilg, H., 2010 The role of cytokines in non-alcoholic fatty liver disease. Dig. Dis. 28: $179-185$.

Tilg, H., and A. R. Moschen, 2010 Evolution of inflammation in nonalcoholic fatty liver disease: the multiple parallel hits hypothesis. Hepatology 52: $1836-1846$. 
Ueki, K., T. Kadowaki, and C. R. Kahn, 2005 Role of suppressors of cytokine signaling SOCS-1 and SOCS-3 in hepatic steatosis and the metabolic syndrome. Hepatol. Res. 33: 185-192.

Vanni, E., E. Bugianesi, A. Kotronen, S. De Minicis, H. Yki-Jarvinen et al., 2010 From the metabolic syndrome to NAFLD or vice versa? Dig. Liver Dis. 42: $320-330$

Wagenknecht, L. E., A. L. Scherzinger, E. R. Stamm, A. J. Hanley, J. M. Norris et al., 2009 Correlates and heritability of nonalcoholic fatty liver disease in a minority cohort. Obesity (Silver Spring) 17: 1240-1246.

Wang, C. Y., D. S. Stapleton, K. L. Schueler, M. E. Rabaglia, A. T. Oler et al., 2012 Tsc2, a positional candidate gene underlying a quantitative trait locus for hepatic steatosis. J. Lipid Res. 53: 1493-1501.

Wang, Y., M. Zhou, K. S. Lam, and A. Xu, 2009 Protective roles of adiponectin in obesity-related fatty liver diseases: mechanisms and therapeutic implications. Arq. Bras. Endocrinol. Metabol. 53: 201-212.

Wanless, I. R., and J. S. Lentz, 1990 Fatty liver hepatitis (steatohepatitis) and obesity: an autopsy study with analysis of risk factors. Hepatology 12: 1106-1110.

Watson, P. M., S. P. Commins, R. J. Beiler, H. C. Hatcher, and T. W. Gettys, 2000 Differential regulation of leptin expression and function in A/J vs.
C57BL/6J mice during diet-induced obesity. Am. J. Physiol. Endocrinol. Metab. 279: E356-E365.

Wilfred de Alwis, N. M., and C. P. Day, 2008 Genes and nonalcoholic fatty liver disease. Curr. Diab. Rep. 8: 156-163.

Willner, I. R., B. Waters, S. R. Patil, A. Reuben, J. Morelli et al., 2001 Ninety patients with nonalcoholic steatohepatitis: insulin resistance, familial tendency, and severity of disease. Am. J. Gastroenterol. 96: 2957-2961

Winzell, M. S., and B. Ahren, 2004 The high-fat diet-fed mouse: a model for studying mechanisms and treatment of impaired glucose tolerance and type 2 diabetes. Diabetes 53(Suppl 3): S215-S219.

Ye, D., F. Y. Li, K. S. Lam, H. Li, W. Jia et al., 2012 Toll-like receptor-4 mediates obesity-induced non-alcoholic steatohepatitis through activation of X-box binding protein-1 in mice. Gut 61: 1058-1067.

Zain, S. M., R. Mohamed, S. Mahadeva, P. L. Cheah, S. Rampal et al., 2012 A multi-ethnic study of a PNPLA3 gene variant and its association with disease severity in non-alcoholic fatty liver disease. Hum. Genet. 131: 1145-1152.

Communicating editor: D. W. Threadgill 